\title{
Parents Motivation for Participation in Physical Activity for Children with Impairments
}

\author{
Wei-Ru "Andy" Yao, Deborah R. Shapiro \\ Georgia State University, United States \\ Chu-Min Liao \\ National Taiwan Sport University, Taiwan, Republic of China
}

\begin{abstract}
The purpose of this study was to examine the effects of impairment type, child's gender, and parent's gender on parent's motives for letting their children with various impairments participate in physical activity. Participants were 184 Taiwanese parents ( $\mathrm{n}=78$ fathers, $\mathrm{n}=106$ mothers) of elementary school age children with impairments. Parents' motives were assessed using the revised Exercise Participation Motives (EPM) scale (Wu \& Liao, 2011). Parents rated personal fitness and skill improvement, positive emotion and friendship, and teamwork as the top three reasons for their child's participation in physical activity. Differences in parents' motives by impairment and child's gender were not statistically significant. A significant effect of parent's gender on parents' motives was found only for the social enhancement construct on the EPM. The cross cultural similarity of the findings and impact of the results in regard to program planning and implementation for children with impairments and their families are discussed.
\end{abstract}

Keywords: cross cultural, gender appropriateness, physical activity engagement

Participation in physical activity has been linked to many benefits for the general population, such as increasing health-related quality of life (Rejeski, Brawley, \& Shumaker, 1996), promoting self-esteem and psychological well-being (Horn \& Claytor, 1993; Whitehead \& Corbin, 1997), decreasing cardiovascular diseases and other secondary health conditions (Nocon, Hiemann, MüllerRiemenschneider, Thalau, Roll, \& Willich, 2008), and developing motor skills, fitness, social competence, and friendships (Pellegrini \& Smith, 1998). Similar research results have been found in people with impairments (Blinde \& McClung, 1997; Dunn \& Dunn, 2006; Martin, Eklund, \& Mushett, 1997; Moola, Faulkner, Kirsh \& Kilburn, 2007; Shapiro \& Martin, 2010, 2014). Children and youth with impairments have reported enjoyment, improved perceptions of competence and athletic identity, increased social acceptance and integration, increased positive and decreased negative affect, and improvements in strength, fitness, and ease of performing activities of daily living as a result of participation in physical activity (Martin, 2013). In fact, physical activity for persons with impairments has been argued to be more important than physical activity for persons without impairments to facilitate participation in daily activities and to reduce the higher rates of secondary health conditions such as obesity, diabetes and heart disease (Martin, 2013; Jaarsma, Dijkstra, Geertzen, \& Dekker, 2014; Jaarsma, Dekker, Koopmans, Dijkstra \& Geertzen, 2014). To maximize the benefits of participation in physical activity, Aarts, Paulussen, and Schaalma (1997), Hirvensalo and Lintunen (2011), and Jaarsma, Dijkstra, Geertzen, and Dekker (2014) recommended that the development of values/motives for exercise to improve health-related quality of life necessary during adulthood should begin in childhood.

The role of the family, specifically parents, plays a significant socializing influence on children's physical activity and sport behavior, cognition, and emotion. The important role of parents can be seen across several theoretical perspectives. According to the parental socialization model (Eccles, Wigfield, \& Schiefele, 1998; PSM), beliefs and expectations for success and task value of parents for activity participation and choices 
significantly influence a child's options and performance on tasks. Based on the rationale of the Theory of Planned Behavior (Ajzen, 1985; Theodorakis, 1994; TPB), parent's attitudes towards physical activity engagement tend to be formed by how the parents perceive and value the benefits of physical activity. These values then influence parent's decisions for their child's exercise and sport participation. Similarly, Harter (1999) identified that parents are the most influential significant others with regards to elementary school age student's involvement in physical activity and healthy exercise behaviors, as well as the findings of Babkes and Weiss (1999) that parents can influence their child's perceived physical competence, emotions, expectations and values about physical activity. Given that children depend on their parents to facilitate their engagement in physical activity (e.g., registering their children for recreational programs, sport camp, facilitating their access to programs, purchasing equipment, and spending time practicing skills), the perceived motives or goals of physical activity participation from the parent's perspective is critical to understanding the involvement of children in physical activity and sport.

Using many of the above theoretical models, researchers have extensively examined the motives of children and youth without impairments towards, physical activity and sport participation and withdrawal (Gill, Gross \& Huddleston, 1983; Klint \& Weiss, 1986). A review article on the barriers and facilitators of sport participation of people with impairments found the research on sport participation motives tended to focus on adults with a single impairment such as intellectual or spinal cord injury and engagement primarily in the sports of wheelchair basketball and swimming (Jaarsma, Dijkstra, Geertzen, \& Dekker, 2014; (Brasile, Kleiber \& Harnisch, 1991; Shapiro, 2003). There is considerably less literature available examining the motives of parents of children with impairments for sport and physical activity engagement. Both Megginson, Nakamura, and Frust (1997) and An and Goodwin (2007) examined parent's reasons for sport and inclusive physical education participation by their children with intellectual impairments and spinal cord injuries, respectively. They similarly reported parents wanted their children to participate for social benefits to increase social contacts, make friends and develop a sense of belonging and to enhance their physical abilities and sport skills. Similar personal motives of fun and relaxation and environmental motives of social contacts were similarly reported by Jaarsma, Dijkstra, Geertzen, and Dekker (2014). The aforementioned research demonstrates parents choose activities for their children with impairments that meet their individual needs, which appear to have some commonality across impairment. It is unclear, however, if the sport participation motives of parents of children with impairments are truly the same across impairment groups. Parent's motives for children with impairments to participate in physical activity have been studied separately based on different types of impairments. Researchers have tended not to investigate the similarities and/or differences in motives for sport and physical activity participation across impairment groups (Jaarsma, Dijkstra, Geertzen, and Dekker (2014). This information may provide continued support for the generalization of motives across impairment classifications and could be invaluable to practitioners responsible for the planning and implementation of sport and physical activity programming for youth with impairments to ensure continued commitment from parents for long term participation in physical activity among children with impairments.

In addition to the effect of impairment type, parents' motives for children's participation in physical activity could be influenced by the child's gender. Kurnik, Kajtna, Bedenik, \& Kovač (2013) found that parents' expectations for enrolling their children in a recreational gymnastics program differed for boys and girls. Three of five parental motives related to competition were rated significantly higher for boys than for girls. These results suggested that the fundamental perception of having different 
motives for boys and girls might lead parents to make different choices for their child's physical activity and sport participation based on their child's gender. Researchers have found support for a gender bias in sport motives and selection such that parents tended to choose more masculine type sports (e.g., basketball, shot put, ice hockey) for boys, and more feminine type activities (e.g., gymnastics, volleyball) for girls (Eccles \& Harold, 1991; Fredrick \& Eccles, 2005; Hargreaves, 1994; Nilges, 1998). Hence, even before a physical activity or sport is selected for a boy or girl, understanding why parents want their children with impairments to participate in physical activity is critical if parents are to be able to advise their child toward a particular sport or physical activity that facilitates regular participation.

Parents' gender is another variable to understanding parents as providers of physical activity experiences. Martin and Mushett (1996) investigated social support mechanisms for athletes with impairments. They found that fathers and mothers provided different types of social support for involvement in sports. Fathers typically provided sport-related information and functional support (practicing with child), while mothers primarily offered non-sport related knowledge and emotional support (comforting the frustration).The differences in social support provided by parents to their children with impairments may reflect differential motives from fathers whose goals for sport participation appeared focused on enhancing their child's skills, competing against others and testing against previous standards to mothers, in contrast, who emphasized more social motives including making friends, enjoying the game, and tension release (Shapiro, 2003). Examining gender of the parents, therefore, is an important consideration for understanding parents' reasons for their children's participation in physical activity.

The purpose of this study was to investigate parent's (fathers or mothers) motives for physical activity participation for their children with impairments. The research questions guiding this study included (a) Why do parents want their children with impairments to participate in physical activity? (b) Do parents' motives differ by their child's impairment, child's gender or parent's gender?

\section{Method}

\section{Participants}

A total of 184 Taiwanese parents $(n=78$ fathers; $\mathrm{n}=106$ mothers) with elementary school age children $(n=113$ boys; $n=71$ girls $)$ with impairments in grades 1 to 6 participated in the study. Children's impairments included physical (PI; $\mathrm{n}=42)$, hearing $(\mathrm{HI} ; \mathrm{n}=35)$, visual (VI; $n=7)$, and intellectual (II; $n=100)$. Severity of the children's impairment was categorized as mild, moderate or severe based on impairment cards issued by the Ministry of Health and Welfare of Taiwan. Parents were eligible to participate in this study if they met the following conditions (a) had an elementary age child with a physical, hearing, visual or intellectual impairment and (b) had a child studying at a special school and/or in a selfcontained classroom in a general school in Taiwan. Data on which participants came from inclusive or self-contained classes was not recorded. Approval to conduct this study was obtained from the primary author's university at the time data was collected, administrators and teachers at the schools from which the parents were recruited, and the parents themselves.

\section{Measures}

Demographic Scale. A parent, either the mother or father self-selected to complete a demographic form including their gender, child's gender, child's date of birth, child's grade, child's impairment type, and severity of child's impairment.

Exercise Participation Motives (EPM; $\mathrm{Wu} \&$ Liao, 2011). The EPM is a 33-item questionnaire, containing six constructs. The first category was personal fitness and skill improvement $(\mathrm{n}=9)$. Sample questions included "It keeps them physically fit and stronger" and "He/she can learn new skills." A 
total of 6 statements addressed social expectation and external factors. Sample statements included "His/her best friends want $\mathrm{him} / \mathrm{her}$ to join" and "He/she likes the coaches." The competition and challenge factor contained 6 statements (e.g., "It offers an opportunity to prove himself/herself by competing with others" and "He/she likes challenges"). Social enhancement was the fourth factor with 5 questions (e.g., "He/she could get compliments from others" and "He/she could outperform others"). The positive emotion and friendship factor contained 5 questions such as "He/she enjoys the feelings when performing well." Lastly, two questions comprised the teamwork variable (e.g., "He/she can work with others to achieve mutual goals").

The original EPM questionnaire was developed for children and youth without impairments to understand why they participate in physical activity. In the present study, however, the parents were the primary respondents so the stem of each question was changed from "I exercise because..." to "I want my child to participate in physical activity because..." Parents answered each question on a 5-point Likert type-scale from 1 (strongly disagree) to 5 (strongly agree).

Original exploratory factor analysis of the EPM was determined from a sample of 3,321 typically developing children and youth (1701 boys and 1620 girls) and resulted in a sixfactor model explaining $49.7 \%$ of the total variance (Wu \& Liao, 2011). A total of 4 of the 33 items, however loaded below .40 on the EPM (two items from the personal fitness and skill improvement factor, one question from the competition and challenge factor, and one question from the positive emotion and friendship factor). According to the suggestions of Stevens (2004) using a cut-off of 0.4 factor loading, these four items were removed from data analyses in the present study leaving a total of 29 items with factor loadings above .40 on the revised EPM used in the present study. Factor loading for the remaining items on the personal fitness and skill improvement ranged from .44 to .73, from .45 to. 75 for the social expectation and external factor, from .44 to .64 on the competition and challenge construct, from .45 to .72 on the social enhancement factor, from .40 to .57 on the positive emotion and friendship factor, and from .66 to .67 on the teamwork construct. All the subscales on the revised EPM yielded acceptable reliability based on a criterion of 0.70 (Hopkins, 2000) $(\alpha=.84$ for fitness and skill improvement; $\alpha$ $=.77$ for social expectation and external factors; $\alpha=.75$ for competition and challenge; $\alpha=.80$ for social enhancement; $\alpha=.77$ for positive emotion and friendship; $\alpha=.74$ for teamwork).

\section{Procedures}

The first author contacted school administrators and teachers to explain the purpose of the investigation, to obtain permission to conduct the study, and to determine the student population. The first author visited some of the schools, clarifying the purpose of the study to students and teachers in person. For the schools the authors were unable to visit in person, the first author mailed to the teachers the number of questionnaires to correspond to the number of students with impairments in each of their respective classes. The teachers read a prewritten script to the students explaining the nature of the study. In all cases, students brought a questionnaire with an instruction note back to either their father or mother for completion. One parent was asked to complete the questionnaires and returned it to their child's teacher within one week. Two weeks after the initial request to participate, the authors contacted the teachers to remind them to encourage parents to complete and return the questionnaire.

A total of 662 questionnaires were sent out to parents at 30 elementary and special schools. In the end, 288 questionnaires were recovered. The overall response rate was $44 \%$. Two criteria were used to screen the valid dataset in this study. Questionnaires were removed from analysis if any of the following 
conditions appeared: (a) more than two missing values out of 33 questions and (b) children were identified as having had multiple impairments. After the screening, 184 questionnaires were valid. The valid questionnaire rate was $64 \%$.

\section{Data Analysis}

First, confirmatory factor analysis (CFA) was used to verify the composition and structure of the revised EPM through LISREL software, and a number of these indices (e.g., Normed Fit Index, Comparative Fit Index, Incremental Fit Index, Root Mean Square Error of Approximation) were used to evaluate the model fit in CFA analysis. Second, mean scores and standard deviations for motive subscales were calculated for parent's gender, child's gender and impairment group and used to provide an overall rank ordering of reasons for their child's participation in physical activity. Third, three one-way MANOVAs were conducted to analyze the differences of parents' motives by parent gender, children's gender, impairment types, and severity of impairment on each of the six motive categories. In order to counteract the problem of multiple comparisons and to reduce the type I errors, the alpha level was adjusted to 0.017 (0.05 / 3) (Bland \& Altman, 1995). Bonferroni correction of post-hoc tests and effect size of significant differences were reported for all significant differences in motives (Tabachnick \& Fidell, 2007; Sullivan \& Feinn, 2012). Effect Sizes $(d)$ of above 0.8 , between 0.8 and 0.5 , between 0.5 and 0.2 and lower than 0.2 were considered as large, moderate, small, and trivial, respectively (Cohen, 1988).

\section{Results}

\section{CFA Results}

The results of the CFA on the revised EPM indicated that the Normed Fit Index (NFI $=.90)$, Comparative Fit Index $(\mathrm{CFI}=.93)$, and Incremental Fit Index (IFI $=.93$ ), three indicators of global model fit used for small sample size, and Root Mean Square Error of Approximation (RMSEA $=.09$ ), an indicator for assessing discrepancy between the implied and observed correlation matrices all indicated acceptable model fit (Tabachnick \& Fidell, 2007).

\section{Descriptive Results}

Impairment groups. For parents of children with physical and visual impairments, both personal fitness and skill improvement $(\mathrm{M}=$ 4.17, $\mathrm{SD}=.66 ; \mathrm{M}=4.00, \mathrm{SD}=.58)$ and teamwork $(\mathrm{M}=4.10, \mathrm{SD}=.71 ; \mathrm{M}=3.86, \mathrm{SD}$ $=.63)$ were respectively placed at first and second in importance. In contrast, parents of children with hearing and intellectual impairments had teamwork at second place $(\mathrm{M}$ $=4.24, \mathrm{SD}=.74 ; \mathrm{M}=3.89, \mathrm{SD}=.74)$, and then personal fitness and skill improvement $(\mathrm{M}=4.11, \mathrm{SD}=.83 ; \mathrm{M}=3.87, \mathrm{SD}=.58)$. Across impairment groups, parents consistently ranked positive emotion and friendship as the third most important reason for their children's participation in physical activity with means scores ranging from 3.78 to 4.05 out of 5 points (Table 1).

Table 1 Descriptive Data for Impairment Types on the Revised Exercise Participation Motives Questionnaire

\begin{tabular}{|c|c|c|c|c|c|c|c|c|c|c|c|c|}
\hline \multirow[t]{2}{*}{ Six Categories of Motives } & \multicolumn{3}{|c|}{$\begin{array}{l}\text { Physical } \\
\text { Impairment }\end{array}$} & \multicolumn{3}{|c|}{$\begin{array}{c}\text { Hearing } \\
\text { Impairment }\end{array}$} & \multicolumn{3}{|c|}{ Visual Impairment } & \multicolumn{3}{|c|}{$\begin{array}{l}\text { Intellectual } \\
\text { Impairment }\end{array}$} \\
\hline & Mean & $\mathrm{SD}$ & Rank & Mean & SD & Rank & Mean & SD & Rank & Mean & SD & Rank \\
\hline $\begin{array}{l}\text { Personal Fitness \& Skill } \\
\text { Improvement }\end{array}$ & 4.17 & .66 & 1 & 4.11 & .83 & 2 & 4.00 & .58 & 1 & 3.87 & .58 & 2 \\
\hline $\begin{array}{l}\text { Social Expectation \& } \\
\text { External Factor }\end{array}$ & 3.42 & .65 & 4 & 3.38 & .70 & 4 & 3.39 & .54 & 4 & 3.29 & .61 & 4 \\
\hline Competition \& Challenge & 3.33 & .73 & 5 & 3.33 & .86 & 5 & 3.20 & .49 & 5 & 3.22 & .57 & 5 \\
\hline Social Enhancement & 3.01 & .79 & 6 & 3.13 & .73 & 6 & 3.09 & .38 & 6 & 3.17 & .66 & 6 \\
\hline $\begin{array}{l}\text { Positive Emotion \& } \\
\text { Friendship }\end{array}$ & 3.99 & .59 & 3 & 4.05 & .66 & 3 & 3.85 & .56 & 3 & 3.78 & .62 & 3 \\
\hline Teamwork & 4.10 & .71 & 2 & 4.24 & .74 & 1 & 3.86 & .63 & 2 & 3.89 & .74 & 1 \\
\hline
\end{tabular}


Severity of impairment. Mean scores for the top-three rank reasons showed changes in priority by impairment severity. Parents, who have children with mild or severe impairments, saw positive emotion and friendship $(\mathrm{M}=3.84, \mathrm{SD}=.57 ; \mathrm{M}=3.93, \mathrm{SD}$ $=.65)$ as the most important motive for wanting their children to participate in physical activity. However, second and third place motives were in opposite ordering between mild and severe impairments. For parents of children with mild impairments, teamwork $(\mathrm{M}=3.79, \mathrm{SD}=.66)$ came before personal fitness and skill improvement $(\mathrm{M}=$ $3.74, \mathrm{SD}=.55)$. On the other hand, parents put teamwork $(\mathrm{M}=3.87, \mathrm{SD}=.66)$ on the first place for their children with moderate impairments, and then treated positive emotion and friendship $(\mathrm{M}=3.85, \mathrm{SD}=.59)$ and personal fitness and skill improvement $(\mathrm{M}$ $=3.85, \mathrm{SD}=.61)$ as equally important motives (Table 2).

Table 2 Descriptive Data for Severity of Impairment on the Revised Exercise Participation Motives Questionnaire

\begin{tabular}{lccccccccc}
\hline \multirow{2}{*}{ Six Categories of Motives } & \multicolumn{3}{c}{ Mild } & \multicolumn{4}{c}{ Moderate } & \multicolumn{3}{c}{ Severe } \\
\cline { 2 - 9 } & Mean & SD & Rank & Mean & SD & Rank & Mean & SD & Rank \\
\hline Personal Fitness \& Skill Improvement & 3.74 & .55 & 3 & 3.85 & .59 & 2 & 3.90 & .58 & 2 \\
Social Expectation \& External Factor & 3.34 & .69 & 4 & 3.37 & .59 & 4 & 3.31 & .64 & 4 \\
Competition \& Challenge & 3.20 & .65 & 5 & 3.27 & .63 & 5 & 3.17 & .67 & 5 \\
Social Enhancement & 3.12 & .71 & 6 & 3.18 & .64 & 6 & 2.93 & .72 & 6 \\
Positive Emotion \& Friendship & 3.84 & .57 & 1 & 3.85 & .61 & 2 & 3.93 & .65 & 1 \\
Teamwork & 3.79 & .66 & 2 & 3.87 & .66 & 1 & 3.78 & .75 & 3 \\
\hline
\end{tabular}

Children's gender. The order of parent's reasons for wanting their children with impairments to exercise differed somewhat by the child's gender. The top three reasons for wanting boys across all impairment groups to participate in physical activity were personal fitness and skill improvement $(\mathrm{M}=3.98, \mathrm{SD}$ $=.71)$, followed by teamwork $(\mathrm{M}=3.97$. $\mathrm{SD}$ $=.79)$, and positive emotion and friendship (M $=3.84, \mathrm{SD}=.66)$. The order of reasons changed slightly for girls with impairments. Teamwork $(\mathrm{M}=4.05, \mathrm{SD}=.64)$ appeared to be the most important with personal fitness and skill improvement $(\mathrm{M}=4.00, \mathrm{SD}=.59)$ and positive emotion and friendship $(\mathrm{M}=3.95$, $\mathrm{SD}=.56)$ rated second and third, respectively (see Table 2). Social enhancement, again, was the least important motive for both genders (Table 3).

Table 3 Descriptive Data for Gender on the Revised Exercise Participation Motives Questionnaire

\begin{tabular}{|c|c|c|c|c|c|c|c|c|c|c|c|c|}
\hline \multirow{2}{*}{$\begin{array}{l}\text { Six Categories of } \\
\text { Motives }\end{array}$} & \multicolumn{3}{|c|}{ Boy } & \multicolumn{3}{|c|}{ Girl } & \multicolumn{3}{|c|}{ Father } & \multicolumn{3}{|c|}{ Mother } \\
\hline & Mean & $\mathrm{SD}$ & Rank & Mean & $\mathrm{SD}$ & Rank & Mean & $\mathrm{SD}$ & Rank & Mean & $\mathrm{SD}$ & Rank \\
\hline $\begin{array}{l}\text { Personal Fitness \& } \\
\text { Skill Improvement }\end{array}$ & 3.98 & .71 & 1 & 4.00 & .59 & 2 & 3.91 & .61 & 2 & 4.05 & .70 & 2 \\
\hline $\begin{array}{l}\text { Social Expectation \& } \\
\text { External Factor }\end{array}$ & 3.32 & .65 & 4 & 3.37 & .61 & 4 & 3.42 & .61 & 4 & 3.28 & .64 & 4 \\
\hline $\begin{array}{l}\text { Competition \& } \\
\text { Challenge }\end{array}$ & 3.28 & .71 & 5 & 3.26 & .60 & 5 & 3.37 & .60 & 5 & 3.20 & .70 & 5 \\
\hline Social Enhancement & 3.11 & .70 & 6 & 3.15 & .69 & 6 & 3.26 & .60 & 6 & 3.03 & .75 & 6 \\
\hline $\begin{array}{l}\text { Positive Emotion \& } \\
\text { Friendship }\end{array}$ & 3.84 & .66 & 3 & 3.95 & .56 & 3 & 3.79 & .62 & 3 & 3.95 & .62 & 3 \\
\hline Teamwork & 3.97 & .79 & 2 & 4.05 & .64 & 1 & 3.92 & .77 & 1 & 4.06 & .71 & 1 \\
\hline
\end{tabular}


Parent's gender. Mean scores for the rank ordering of reasons did not differ by parents' gender. Both fathers $(\mathrm{M}=3.92, \mathrm{SD}$ $=.77)$ and mothers $(\mathrm{M}=4.06, \mathrm{SD}=.71) \mathrm{had}$ teamwork at first position, personal fitness and skill improvement $(\mathrm{M}=3.91, \mathrm{SD}=.61$ for fathers and $\mathrm{M}=4.05, \mathrm{SD}=.70$ for mothers) at second and rated positive emotion and friendship $(\mathrm{M}=3.79, \mathrm{SD}=.62$ for fathers and $\mathrm{M}=3.95, \mathrm{SD}=.62$ for mothers) as third in importance (see Table 3). Social enhancement was the least important motive among both fathers and mothers.

\section{MANOVA Results}

Evaluations of assumptions of normality (skewness $=.01 \sim .28$, kurtosis $=.01 \sim .62$ ), multicollinearity (tolerance $=.34 \sim .55, \mathrm{VIF}=$ $1.80 \sim 2.91$ ), and homogeneity of variancecovariance matrices (Box's $\mathrm{M}=1.30 \sim 1.46, p$ $>.05)$ were examined before running MANOVA analysis. The results showed that the data was suitable for multivariate analysis of variance). MANOVA results demonstrated no significant differences in parent's motives for sons and daughters, $\mathrm{F}(6,177)=.59$, Wilks' Lambda $=.98, p>.017$, impairment type differences, $F(18,495.46)=1.30$, Wilk's Lambda $=.88, p>.017$, or impairment severity $F(12,352)=1.09$, Wilk's Lambda $=.93, p>.017$. As a result, the total sample was pooled to examine differences in parent's motives across parents' gender. MANOVA results indicated differences in parent's motives by parents' gender, $\mathrm{F}(6,177)=3.24$, Wilk's Lambda $=.90, p<.017$. Univariate analysis of variance demonstrated that the only difference was found on social enhancement, $\mathrm{F}(1,182)=5.33, p>.05$. Effect size, partial $\eta^{2}=.03$ (small $=.01$; medium $=.09 ;$ large $=.25)$, showed a small difference between fathers and mothers. While ranked sixth out of 6 motives, fathers $(\mathrm{M}=$ $3.26, \mathrm{SD}=.78$ ) had higher social enhancement motive for their children with impairments than mothers $(\mathrm{M}=3.03, \mathrm{SD}=.67)$.

\section{Discussion}

The purpose of the current study was to investigate parent's motives for their children's physical activity participation and if these motives differ by impairment, children's gender, and parent's gender. The findings of the present study indicated that Taiwanese parents, like North American parents value the same goals for their children's exercise and sport participation and that these goals do not differ across impairment categories. Consistent with The Theory of Planned Behavior (Ajzen, 1985; Theodorakis, 1994), parent's attitudes towards physical activity engagement tend to be formed by how the parents perceive and value the benefits of physical activity. These values then influence parent's decisions for their child's exercise and sport participation. The similarity of goals across impairment groups is meaningful in light of limitations of previous studies in which a single impairment group tends to be the focus of the respective studies (Jaarsma, Dijkstra, Geertzen, and Dekker (2014). This study is among the first to confirm that parental motives for sport participation are common across disability suggesting that the benefits from sport participation are human needs regardless of impairment type.

The top three reasons Taiwanese parents have for wanting their children with impairments to participate in physical activity were personal fitness and skill improvement, teamwork, and positive emotion and friendship. These results are consistent with those reported by researchers examining sport participation motives for a single impairment group (An \& Goodwin, 2007; Megginson, Nakamura \& Frust, 1997; Jaarsma, Dekker, Koopmans, Dijkstra, \& Geertzen (2014) and consistent with the self-reported personal and environmental reasons for sport participation by children and adults with impairments in the review study by Jaarsma, Dijkstra, Geertzen, and Dekker (2014) in which they reported, fun, fitness, and social contacts acted as facilitators of sport participation by people with various impairments and across children and adults alike. 
Parent's emphasis on fitness and skill improvement for their children with impairments reflects a motivational focus centered on the development of competence. The importance of personal fitness and skill improvement was rated relatively more important by parents of children with physical and visual impairments. These findings in parents of children with visual impairments are supported by $\mathrm{Wu}$ and colleagues (2008), who reported that primary motives for participating in physical activity were health and improving fitness and skills for individuals with visual impairments in Taiwan because the limits of visual loss may have hindered them from having a healthy lifestyle. Competence for children with physical and visual impairments may go beyond sport skills per say and may focus more on health benefits of participation (Jaarsma, Dekker, Koopmans, Dijkstra \& Geertzen, 2014). Children with impairments tend to experience less physical movement than their typically developing peers. This may be attributed, in part, to contraindications to participation due to health and safety risks associated with the impairment (Jaarsma, Dijkstra, Geertzen, \& Dekker, 2014). In addition, the use of wheelchairs, a lack of understanding of accommodations for vision loss, costs, lack of peer buddies and lack of accessibility and transportation (Jaarsma, Dekker, Koopmans, Dijkstra \& Geertzen, 2014; Jaarsma, Dijkstra, Geertzen, \& Dekker, 2014) all, in and of themselves, individually act as barriers impacting opportunities for engagement in physical activity. An emphasis on fitness also may reflect parent's concerns for their child's ability to independently conduct activities of daily living and increased risk of obesity as a secondary health impairment (An \& Goodwin, 2007). Lastly, given the context and culture of Taiwan, an emphasis on fitness and skill improvement may reflect more organized resources (e.g., summer camps, national games) available for children with physical than for children with other impairments. Thus, parents may have had advanced knowledge about improving their child's skills and fitness beyond just looking for social opportunities for their children through physical activity and sport.

The positive emotion, friendship and teamwork goals all reflect a motivational focus on the development of affiliation. Parents of children with impairments tend to be concerned about increased support required for their children's communication and socialization with others (Kirk, Gallagher, Coleman, \& Anastasiow, 2011; Wu, Huang, Li, \& Chen, 2008). As such, a focus on improving interpersonal skills may be one of the primary reasons for their physical activity participation. The results of the present study are consistent with the research of Moola and colleagues (2007), McCallagh, Matzkanin, Shaw, and Maldonado (1993), An and Goodwin (2007) and Martin (2013) who reported that parents' believed that affiliation (making friends, teamwork, enjoying the activities with peers, and having positive emotions through connecting with friends) were priorities that decreased social isolation and increase positive sense of belonging.

The present findings indicate the lack of impact of parent's gender on motives for their children's sport participation. Mothers and fathers similarly ranked teamwork, personal fitness and skill improvement, and positive emotion and friendship as the primary three motive constructs for their children's participation in physical activity. The similarity in parent ratings is supported by Martin's (2006) research in which he indicated that parental encouragement for participating in physical activity did not vary according to parent's gender.

While not statistically significant, the rank orderings of parents' motives became slightly different when considering the children's gender. Personal fitness and skill improvement was a first consideration for boys when parents wanted them to participate in physical activity. In contrast, the major reason for girls focused on the motive of teamwork. Same as the findings of Kurnik, Kajtna, Bedenik, \& Kovač (2013), they argued that the fundamental perception of parents about physical activity was predominant as the "male activity". Therefore, parents would 
subconsciously rate more masculine benefits for boys rather than for girls.

This finding of potential gender bias can be seen in fathers reported higher scores on social enhancement motive than mothers. Sport has been pervasively recognized as a male domain (Martin, 2006). It is possible that fathers desired for their children to win trophies, get attention from others, and be complimented for their skill. Such beliefs could be easily reflected when wanting their children to exercise. Beside, from fathers past experiences and perspectives, participating in physical activity could be a great tool to gain confidence. These findings are somewhat consistent with past research (Eccles \& Harold, 1991; Fredricks \& Eccles, 2005; Freeman, 2007; Hardin \& Greer, 2009) and the tenants of the parental socialization model (Eccles, Wigfield, \& Schiefele, 1998) that parents' sense of gender appropriateness can be an influential factor on deciding the expectations and options of activity for boys and girls. However, even though parents of children with impairments appeared to have differed in motives based on children's gender, they similarly valued the importance and benefits of participating in physical activity more than following traditional stereotypes to treat boys and girls differently. We do not know, however, whether parental motives influence their child's actual physical activity behaviors. It would be important to test the ideas of the TPB and the PSM on this particular population to see the correlations between motives and actual physical activity behavior levels.

\section{Limitations}

A couple limitations warrant comment. First, with a recovery rate of questionnaires at only $64 \%$ and the sample size of parents of children with visual impairment, the generalization of the results should be done cautiously. Second, the effectiveness of measurement should be mentioned. The EPM was developed for typically developing students. Even though both the CFA and internal consistency test showed acceptable results for the revised EPM, the reliability and validity of the revised EPM for the population in the current study remains uncertain. The validity and reliability of the revised EPM as a parent survey and or proxy survey to compare with children's responses needs further testing.

\section{Perspectives}

Schools, community-based organizations, and nonprofit organizations servicing children with impairments may not need to focus on designing customized classes for different gender of children and different impairment types. The more important consideration is that the programming match what parents want for their children. The central purposes of designing classes and programs for children with impairments are creating more opportunities for these children to improve fitness and sport-related skills, in an environment, either self-contained or inclusive, that fosters a sense of teamwork and develops friendships. Thus, when these goals are met, parents may be more inclined to bring their children to participate in physical activity, the goal of which would be long-term participation for children with impairments to improve their overall physical and emotional health and quality of life.

\section{References}

Aarts, H., Paulussen, T., \& Schaalma, H. (1997). Physical exercise habit: On the conceptualization and formation of habitual health behaviours. Health Education Research, 12, 363-374.

Ajzen, I. (1985). From intentions to actions: A theory of planned behavior. In J. Kuhl \& J. Beckmann (Eds.), Action control: From cognition to behavior. New York: Springer-Verlag.

An, J. \& Goodwin, D.L. (2007). Physical education for students with spinal bifida: Mothers' perspectives. Adapted Physical Activity Quarterly, 24, 38-58.

Babkes, M.L. \& Weiss, M.R. (1999). Parental influence on children's cognitive and affective responses to competitive soccer 
participation. Pediatric Exercise Science, $11,44-62$.

Bland, J.M. \& Altman, D.G. (1995). Multiple significance tests: The Bonferroni method. British Medical Journal, 310, 170.

Blinde, E.M. \& McClung, L.R. (1997). Enhancing the physical and social self through recreational activity: Accounts of individuals with physical disabilities. Adapted Physical Activity Quarterly, 14, 327-344.

Brasile, F.M., Kleiber, D.A., \& Harnisch, D. (1991). Analysis of participation incentives among athletes with and without disabilities. Therapeutic Recreation Journal, 25, 18-33.

Cohen, J. (1988). Statistical power analysis for the behavioral sciences. Hillsdale, NJ: Lawrence Erlbaum Associates.

Dunn, J.C. \& Dunn, J.G.H. (2006). Psychosocial determinants of physical education behavior in children with movement difficulties. Adapted Physical Activity Quarterly, 23, 293-309.

Eccles, J.S., Adler, T.F., Futterman, R., Goff, S.B., Kaczala, C.M., Meece, J.L., \& Midgley, C. (1983). Expectancies, values, and academic behaviors. In J. T. Spence (Ed.), Achievement and achievement motivation (pp. 75-146). San Francisco, CA: W. H. Freeman.

Eccles, J.S. \& Harold, R.D. (1991). Gender difference in sport involvement: Applying the Eccles' expectancy-value model. Journal of Applied Sport Psychology, 3, 7-45.

Eccles, J.S., Wigfield, A., \& Schiefele, U. (1998). Motivation to succeed. In W. Damon (Series Ed.) and N. Eisenberg (Vol. Ed.), Handbook of child psychology (5th ed., Vol. III, pp. 1017-1095). New York: Wiley.

Fredricks, J.A. \& Eccles, J.S. (2005). Family socialization, gender, and sport motivation and involvement. Journal of Sport \& Exercise Psychology, 27, 3-31.

Freeman, N.K. (2007). Preschoolers' perspective of gender appropriate toys and their parents' beliefs about genderized behaviors: Miscommunication, mixed messages, or hidden truths? Early Childhood Education Journal, 34, 357366.

Gill, D.L., Gross, J.B., \& Huddleston, S. (1983). Participation motivation in youth sports. International Journal of Sport Psychology, 14, 1-14.

Hardin, M. \& Greer, J.D. (2009). The influence of gender-role socialization, media use and sports participation on perceptions of gender-appropriate sports. Journal of Sport Behavior, 32, 207-226.

Hargreaves, J. (1994). Sporting females: Critical issues in the history and sociology of women's sports. London: Routledge.

Harter, S. (1999). The construction of the self: $A$ developmental perspective. New York: Guilford Press.

Hirvensalo, M. \& Lintunen, T. (2011). Lifecourse perspective for physical activity and sports participation. European Reviews of Aging \& Physical Activity, 8, 13-22.

Hopkins, W.G. (2000). Measures of reliability in sports medicine and science. Sports Medicine 30, 1-15.

Horn, T.S. \& Claytor, R.P. (1993). Developmental aspects of exercise psychology. In P. Seraganian (Ed.), Exercise psychology: The influence of physical exercise on psychological processes (pp. 299-338). New York: John Wiley \& Sons.

Jaarsma, E.A., Dijkstra, P.U., Geertzen, J.H.B., \& Dekker, R. (2014). Barriers to and facilitators of sports participation for people with physical disabilities: A systematic review. Scandinavian Journal of Medicine and Science in Sports, 24, 871-881.

Jaarsma, E.A., Dekker, R., Koopmans, S.A., Dijkstra, P.U., \& Geertzen, H.B. (2014). Barriers to and facilitators of sports participation in people with visual impairments. Adapted Physical Activity Quarterly, 31, 240-264.

Kirk, S., Gallagher, J., Coleman, M.R., \& Anastasiow, N. (2011). Educating 
exceptional children (13th ed.). Boston: Houghton Mifflin.

Klint, K.A., \& Weiss, M.R. (1986). Dropping in and dropping out. Participation motives of current and former youth gymnasts. Canadian Journal of Applied Sport Sciences, 11, 106-114.

Kurnik, J.F., Kajtna, T., Bedenik, K., \& Kovač, M. (2013). Why parents enroll their children in recreational gymnastics programmes at the beginning of their education. Science of Gymnastics Journal, $5,41-52$

Martin, J.J. (2006). Psychosocial aspects of youth disability sport. Adapted Physical Activity Quarterly, 23, 65-77.

Martin, J.J. (2013). Benefits and barriers to physical activity for individuals with disabilities: A social relational model of disability perspective. Disability and Rehabilitation,35(24), 2030-2037.

Martin, J.J., Eklund, R.C., \& Mushett, C.A. (1997). Factor structure of the Athletic Identity Measurement Scale with athletes with disabilities. Adapted Physical Activity Quarterly, 14, 74-82.

Martin, J.J. \& Mushett, C.A. (1996). Social support mechanisms of athletes with disabilities. Adapted Physical Activity Quarterly, 13, 74-83.

McCullagh, P., Matzkanin, K.T., Shaw, S.D., \& Maldonado, M. (1993). Motivation for participation in physical activity: A comparison of parent-child perceived competencies and participation motives. Pediatric Exercise Science, 5, 224-233.

Megginson, N.L., Nakamura, A., \& Frust, D.M. (1997). Parental perception of Special Olympics benefit and outcomes. Palaestra, 13, 12-14.

Moola, F., Faulkner, G.E.J., Kirsh, J.A., \& Kilburn, J. (2007). Physical activity and sport participation in youth with congenital heart disease: Perception of children and parents. Adapted Physical Activity Quarterly, 25, 49-70.

Nilges, L.M. (1998). I thought only fairy tales had supernatural power: A radical feminist analysis of Title IX in physical education. Journal of Teaching in Physical Education 17, 172-94.

Nocon, M., Hiemann, T., MüllerRiemenschneider, F., Thalau, F., Roll, S., \& Willich, S.N. (2008). Association of physical activity with all-cause and cardiovascular mortality: A systematic review and meta-analysis. European Journal of Cardiovascular Prevention \& Rehabilitation, 15, 239-246.

Pellegrini, A.D. \& Smith, P.K. (1998). Physical activity play: The nature and function of a neglected aspect of play. Child Development, 69, 577-598.

Rejeski, W.J., Brawley, L.R., \& Shumaker, S.A. (1996). Physical activities and health-related quality of life. Exercise and Sport Sciences Review, 24, 71-108.

Stevens, J.P. (1992). Applied multivariate statistics for the social sciences (2nd edition). Hillsdale, NJ: Erlbaum.

Shapiro, D.R., (2003). Participation motives of Special Olympics athletes. Adapted Physical Activity Quarterly, 20, 150-165.

Shapiro, D.R., \& Martin, J.J. (2010). Athletic identity, affect and peer relations in youth athletes with physical disabilities. Disability and Health Journal, 3, 79-85.

Shapiro, D.R., \& Martin, J.J. (2014). The relationship among sport self-perception and social wellbeing in athletes with physical disabilities. Disability and Health Journal, 7, 42-48.

Sullivan, G. M. \& Feinn, R. (2012). Using effect size - or why the $\mathrm{P}$ value is not enough. Journal of Graduate Medical Education, 4, 279-282.

Tabachnick, B. G., \& Fidell, L. S. (2007). Using multivariate statistics (5th ed.). Boston, Massachusetts: Allyn and Bacon.

Theodorakis, Y. (1994). Planned behavior, attitude strength, role identity, and prediction of exercise behavior. The Sport Psychologist, 8, 149-165.

Whitehead, J.R. \& Corbin, C.B. (1997). Selfesteem in children and youth: the role of sport and physical education. In K.R. Fox, (Ed.), The physical self: From motivation to well-being (pp.59-82). Human Kinetics, Champaign, IL. 
Wu, H.T. \& Liao, C.M. (2011). Participation in physical activities for 9 to 15 year-old Taiwan students' gender and age differences in motives. Physical Education Journal, 44, 407-422.

Wu, S.K., Huang, M.H., Li, Y.C., \& Chen, W.Y. (2008). Sport participation and barriers among people with visual impairments in Taichung. Journal of Health Promotion, 3, 33-47. 